The Polish Journal of the Arts and Culture. New Series 6

(2/2017): 53-76 [ARTICLE]

DOI: $10.4467 / 24506249$ PJ.17.010.8764

\title{
Ashé pa' todos. Los santeros en México y sus agentes divinos
}

\author{
Nahayeilli B. JuÁREz Huet
}

\begin{abstract}
Resumen
El presente artículo describe cómo opera en la vida religiosa cotidiana, la red de relaciones entre los iniciados en la santería afrocubana, y entre éstos y las figuras sagradas a las que veneran, representadas por los orisha. Lejos de agotar la vasta riqueza de la santería en tanto religión vivida, recupero sólo la ceremonia del toque de tambor como un ejemplo ilustrativo de la complejidad que encierran dichas relaciones dentro del contexto mexicano, en donde por un lado existe una regulación social que desautoriza la diversidad religiosa de la que la santería forma parte, y por el otro, una dislocación entre afiliaciones religiosas, prácticas y creencias, que denotan una desinstitucionalización de lo religioso observada en general en la América Latina contemporánea.
\end{abstract}

Palabras clave: Religión vivida, santería, México, toque de tambor, orisha

Nahayeilli B. JuÁREz HuET es Antropologa Social y profesora investigadora en el Centro de Investigaciones y Estudios Superiores en Antropología Social en la sede Peninsular. Sus temas de interés versan sobre la circulación de las religiones afroamericanas y las nuevas espiritualidades New Age.

E-MAIL: nahahuet@ciesas.edu.mx 


\section{Los orisha y espíritus están en todas partes}

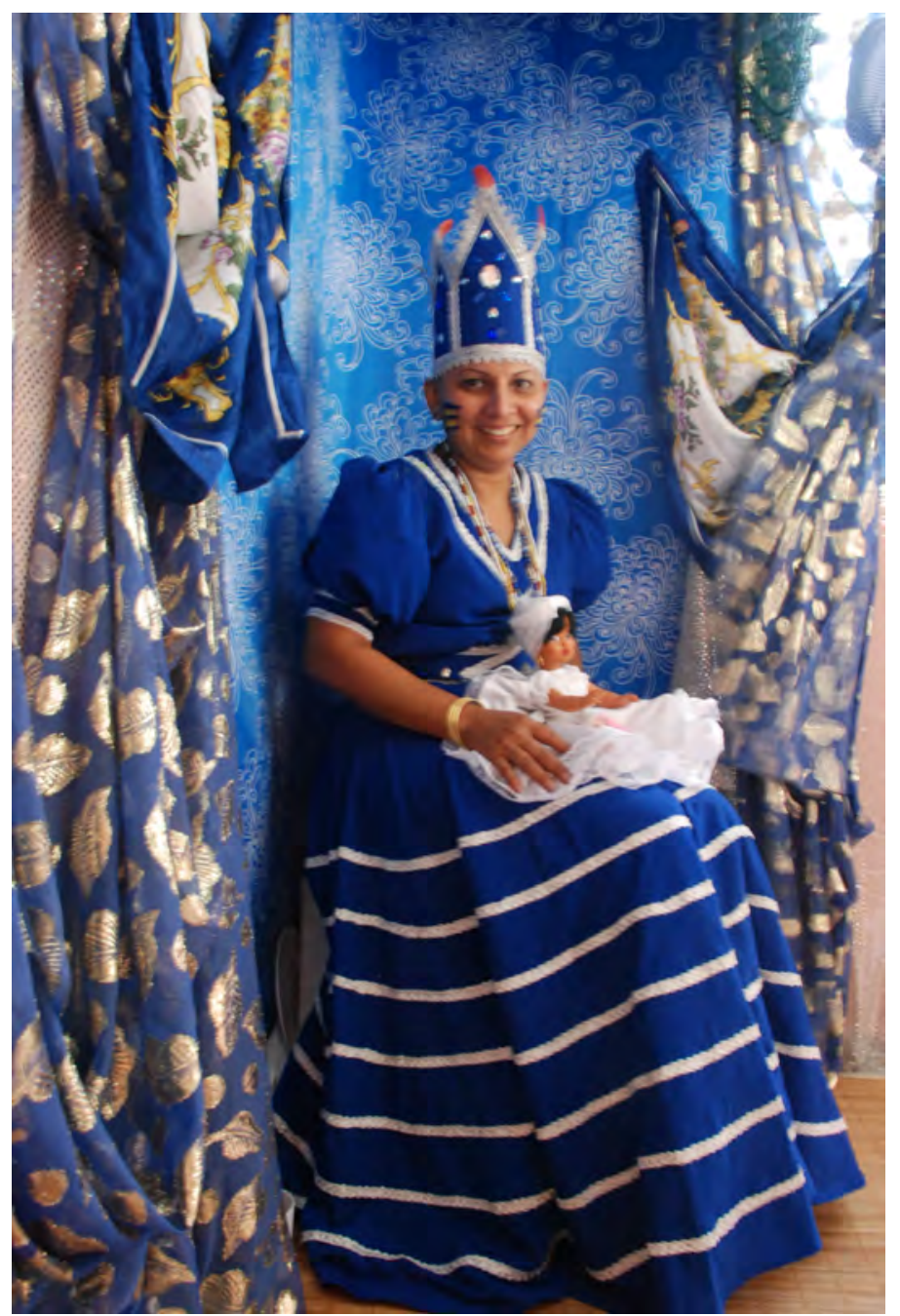

Figura 1: Mexicana, hija de Yemayá recién iniciada en su traje de gala. La Habana, Cuba, marzo de 2013. (Foto: Nahayeilli Juárez Huet)

Todos los llamados orisha (a los que se les refiere entre mexicanos y cubanos de forma indistinta como "santos") fueron enviados a poblar la tierra por Olodumare, el Dios creador en la cosmogonía yoruba y las religiones afroamericanas emparentadas históricamente con la misma, ${ }^{1}$ tales como la

\footnotetext{
1 Yoruba es una categoría étnica que designa a los originarios del sudoeste de Nigeria y parte
} 
santería cubana, practicada en México desde mediados de los años 70. Todos y cada uno de estos orisha representan diversos elementos de la naturaleza y son las figuras centrales y mediadoras de las relaciones entre los humanos y Olodumare, pues concentran y transmiten su poder: el $a s h e^{2}$. En la santería, cada individuo es considerado hijo de un determinado orisha, asignado luego de los rituales de adivinación correspondientes, y después, asentado (o coronado) simbólicamente en la cabeza de los iniciados en donde tendrá su "morada". A partir de esta iniciación, el orisha revelado regirá desde ese momento a su iniciado (olorisha), e idealmente se convertirá en un aliado personalizado, poderoso confidente y protector. En Cuba y México, a este orisha tutelar o "coronado", se le llama también ángel de la guarda ${ }^{3}$, evocando la fuerte referencia a un catolicismo por siglos dominante, pero sobre todo al papel de protector de esta figura, salvo que los orisha son entidades con las que sus devotos, a diferencia del ángel de la guarda o los santos católicos, se pueden comunicar y obtener respuestas concretas por medio de la adivinación, la mediumnidad, la posesión y otros medios "menos oficiales" (institucionalmente hablando), como son los sueños o visiones.

Cuando una persona recibe los fundamentos y "secretos" que corresponden a las distintas ceremonias 4 de iniciación en la santería, se dice que, "adquiere fuerza, estará protegido, tendrá salud, bienestar, suerte, tranquilidad, y todas las cosas buenas de la vida”. En las malas, cuando no se comprende cabalmente el infortunio, la pena o la tragedia, este orisha podrá ser una importante fuente de templanza y consuelo para abrirle camino a su devoto. Pero también, se le toma como el autor de situaciones difíciles, como una forma de poner a prueba a sus hijos o de manifestar su descontento. A veces uno se encuentra con que los devotos lo llevan de paseo, o de viaje, portando para ello la representación material del orisha en cuestión, como un soporte material de su fe. Estas deidades, sin embargo, lo mismo pueden ser objeto de castigo, cuando no "cumplen" lo que su iniciado espera de ellos y en casos

del actual Benin y Togo y está ligada a la tradición orisha a la que pertenece la santería como una de sus variantes.

2 En Cuba se pronuncia y escribe aché. En México se usan ambas.

3 O Ángel de la guardia.

4 En la santería hay iniciaciones "menores", como son los collares, los guerreros y mano o ikofá de Orula, por mencionar sólo las principales. Para poder ser considerado(a) como santero(a) la persona deberá pasar por la ceremonia que se conoce como la coronación del santo. Lo mismo sucederá con los máximos sacerdotes conocidos como babalawo, considerados como tales después de haber pasado por la ceremonia de Ifá. 
extremos, ser materialmente "desechados". Se trata pues de un vínculo que se humaniza, estableciéndose una relación de interdependencia muy personal y única, al grado de identificar la propia personalidad con el arquetipo del orisha "asentado" o "coronado" durante la iniciación ${ }^{5}$. Es también una relación más horizontalizada que no requiere necesariamente de un intermediario, lo cual se esgrime como una de las razones más comunes entre santeros para adentrarse en esta religión.

Los orisha habitan en muchos lugares de la naturaleza, como el mar, el río, el bosque; pero también se hacen presentes en muchos lugares del paisaje urbano y el suelo que pisamos cotidianamente. En el mercado por ejemplo vive la orisha Oyá, pero también posee la potestad de las puertas del cementerio por su estrecha relación con Ikú, la muerte; en las vías de un tren puede estar presente Ogún, el orisha dueño de los metales; en los cruceros o en las esquinas, Elegúa, el trickster y dueño de las encrucijadas. En la cárcel y sus perímetros puede evocarse a Ochosi, el orisha cazador asociado a la justicia. En todos estos espacios es posible llevar a cabo rituales para negociar, apaciguar y propiciar los poderes de estos agentes, que junto con los muertos (espíritus) constituyen los poderes invisibles a los que se dirigen las acciones rituales de todo santero u olorisha. En efecto, en las religiones afroamericanas, herederas del culto a los ancestros en África subsahariana, los espíritus y muertos son piezas angulares de la vida religiosa cotidiana. No están en un "cielo" abstracto, sino habitando muy cerca de uno, se les ve, se les oye, y también se les apacigua y da luz, a usanza del catolicismo y del espiritismo que cobró arraigo en América Latina desde el siglo XIX, y que forma parte de la santería que nació en Cuba y que circuló después a México. ${ }^{6}$

Para comprender así la relación de los santeros con estos agentes divinos, propongo como herramienta heurística el concepto de religión vivida de Robert A. Orsi, definida como una red de relaciones entre el mundo visible y las figuras sagradas del mundo invisible. "Estas relaciones involucran todas las complejidades -esperanzas, evasiones, amor, miedo, negación, proyecciones, malentendidos, y así sucesivamente- de las relaciones humanas" ${ }^{\text {. En la }}$

5 La coronación es una iniciación mayor y nodal en este sistema religioso, sin embargo, también existen otro grupo de iniciaciones menores por medio de las cuales el sujeto en cuestión va adquiriendo conocimiento y soportes materiales conocidos como fundamentos, por medio de los cuales las entidades del mundo invisible son invocadas y representadas.

6 Otras denominaciones de esta religión son: Regla de Ocha, Religión Lucumí, Religión yoruba.

7 El autor señala que esta relación es entre el cielo y la tierra, evocando al mundo cristiano. Yo prefiero hablar del mundo visible e invisible. R. A. Orsi, Between Heaven and Earth: The 
compañía de estas figuras sagradas las personas se van abriendo camino y resolviendo su cotidianidad. Los efectos de estas relaciones pueden apreciarse justamente en el terreno de las prácticas y experiencias vividas de la gente. La religión vivida no puede extraerse por tanto de otras prácticas de la cotidianidad ni tampoco de las relaciones de poder que le acompañan. ${ }^{8} \mathrm{Se}$ aprecia igualmente a través de las relaciones entre creyentes y practicantes mediadas en muchos sentidos por estos agentes sagrados.

De esta manera, el presente artículo ilustra lo anterior a partir de una de las expresiones rituales cotidianas más importantes dentro de la santería, a saber: el toque de tambor; y a la vez, esboza grosso modo elementos del contexto histórico y cultural mexicano en el que esta religión se relocaliza a partir de sus actores cotidianos. ${ }^{9}$

\section{Toque de tambor: redes de reciprocidad e inter- cambio}

Yemayá es el orisha tutelar de Othón, un hombre nacido en Mérida, Yucatán (sureste de México) en 1978, cuyo padre biológico lo llevó, como un último recurso, con un santero a ver si éste podía ayudarlo a salir de los "malos pasos" que tenían a toda la familia preocupada. Fue gracias a este santero, originario de la Ciudad de México (CDMX) que Othón se familiarizó con la santería y se interesó en los orisha, luego de que en efecto, la intervención de este santero influyera positivamente en su vida. Con este hombre, Othón también recibió algunas iniciaciones menores y sus fundamentos correspondientes. Este mismo santero lo llevó años después con una pareja de cubanos que contaban con las redes y soportes materiales necesarios para ceremonias mayores. Se trataba de un matrimonio que radicó en Mérida un tiempo, en donde la santería, a diferencia de la ciudad capital mexicana (CDMX), tiene apenas una veintena de años. Esta pareja fue la que finalmente orquestó las iniciaciones mayores de Othón en el 2005, año en el que se coronó y se inició como hijo de Yemayá.

Religious Worlds People Make and the Scholars Who Study Them, p. 3.

8 R. Orsi, Is the Study of Lived Religion Irrelevant to the World We Live in?, p. 172.

9 Por relocalización entiendo un proceso que implica desanclajes de prácticas culturales que en su circulación se reanclan en distintas latitudes geográficas, sociales y culturales y en donde otros marcos interpretativos reajustan sus sentidos, dando lugar a otras apropiaciones en su praxis, representación y materialización (para diversos ejemplos de relocalización religiosa en México véase Argyriadis y De la Torre, 2008). 


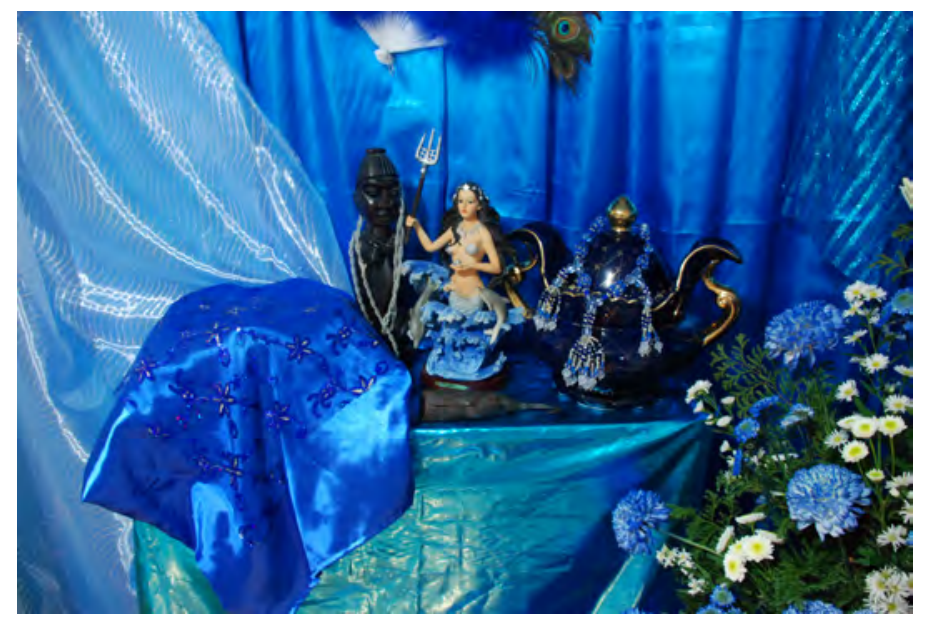

Figura 2: Detalle del trono de Othón. Representaciones cubana y nigeriana de Yemayá. Mérida, yucatán, enero de 2013. Foto: Nahayeilli Juárez Huet.

El orisha Yemayá (Yémojá en yoruba) cuyo origen y morada original se encuentra en el río Ogun de la ciudad de Abéokuta, Nigeria -nos explica Pierre Verger- "es la divinidad de las aguas de mar y de las aguas dulces", madre de todos los orisha y símbolo por excelencia de la maternidad entre los yoruba de África occidental. ${ }^{10}$ Después de que cruzara el Atlántico con los africanos esclavizados y traídos a América durante casi cuatro siglos, mantiene la imagen de madre protectora, pero sólo gobierna sobre las aguas saladas.

Para celebrar el aniversario de su iniciación, el cual Othón considera como "lo más grande que le ha sucedido en la vida", decidió ofrecer a esta reina del mar un toque de tambor. En esta ocasión, también tenía previsto honrar a la deidad del río y la fertilidad, Oshún, la orisha que coronó su joven esposa de origen cubano a la que conoció en este medio religioso. Debido a que sus aniversarios de santo están muy próximos y al desembolso económico y la compleja organización que implica un toque de tambor, decidieron festejarlas en el mismo evento.

El toque de tambor (wemilere) o simplemente tambor como comúnmente se le refiere, es una de las ceremonias más populares en la santería. En efecto, esta fiesta a menudo se convoca cuando uno cumple años de haber coronado su cabeza, o bien, si así está estipulado en la lista de los deberes dispuestos por el orisha titular. Muchas veces a los orisha se les ofrenda esta ceremonia como

${ }^{10}$ P. Verger, Dieux d'Afrique, p. 312. 
señal de agradecimiento, como la manda ${ }^{11}$ adquirida por haber ayudado al "hijo" en cuestión a conseguir o lograr algún objetivo, a paliar alguno de sus males, a salvarlo de morir.

A los toques de tambor se invitan amigos, familiares y correligionarios. La celebración se realiza generalmente en las residencias particulares de los iniciados en donde también disponen sus templos, pues esta religión carece de organizaciones eclesiales o una sola figura alrededor de la cual se aglutinen todos sus creyentes. En Cuba, los toques de tambor son normalmente abiertos al público. En México, esta situación cambia por razones de seguridad, especialmente en los últimos años que el crimen organizado y la violencia han ido en escalada, y porque la religión no goza aún de un prestigio social y familiaridad amplia como para dejar la puerta abierta a los extraños. A pesar de los cambios de enfoque para comprender la alteridad religiosa en México, en donde se ha pasado relativamente de un lenguaje de sectas a uno de diversidad religiosa, en la percepción común, muchos de los fantasmas construidos desde hace ya algunos siglos hacia las religiones "afro" (como algo oscuro, salvaje, demoniaco y primitivo) perviven, y con ello se acentúan las distancias sociales entre sus practicantes y los ajenos. Este "otro", el santero, permanece en un amplio sector de la población como un "extranjero" en términos de Simmel ${ }^{12}$. No es casualidad que la experiencia social de la diferencia religiosa sea más llevadera en una ciudad como México, la ciudad más liberal de todas las del país, que por ejemplo, en la Zona Metropolitana de Mérida, Yucatán, una capital regional conservadora, en donde la santería no circula de manera tan intensa y veloz y que es todavía menos familiar. En el contexto mexicano en general existe una regulación social que desautoriza -y es también ambigua- con respecto a la diversidad religiosa de la que la santería forma parte visible, desde al menos los años 9o. Por lo regular se le coloca fuera de lo "legítimamente religioso" y muy a menudo se le estigmatiza. Los santeros en Mérida, por ejemplo, expresan: "Mis vecinos me tienen miedo porque piensan que soy brujo"13; "Sí, la religión ha crecido, pero con muchos obstáculos porque es muy conservadora esta ciudad. La gente me ve raro. Me han llamado a la policía por los animales [...porque piensan] que estoy haciendo ritos satánicos [...]"14. "Aquí [en Mérida] la gente es muy ce-

${ }^{11}$ En México, se le conoce popularmente como "manda" a la promesa que el devoto hace a un santo, vírgen, Cristo. En México las mandas tienen un fuerte marco referencial al catolicismo.

${ }^{12} \mathrm{G}$. Simmel, El extranjero. Sociología del extraño.

${ }^{13}$ Conversación con Jorge J., Mérida, Yucatán, 31 de enero de 2015.

${ }^{14}$ Entrevista a Nelson. Q., Mérida, Yucatán, 28 de agosto de 2008. 
rrada, [...] fue muy difícil para toda mi familia aceptar [que soy santera]"15. Al mismo tiempo, y paradójicamente, los devotos y practicantes no parecen disminuir, sino todo lo contrario; por lo común despliegan diversas estrategias para ocultar su adscripción religiosa, que a menudo es múltiple, es decir, que los santeros en México (como en Cuba) también son católicos, espiritistas, paleros ${ }^{16}$ y más.

El toque de tambor es una ceremonia difícil de ocultar porque asisten decenas de personas que cantan y bailan a ritmo de los tambores batá (trío de tambores sagrados) batidos por percusionistas especializados y consagrados en el tambor; y el cantante ritual (Apwón). A menudo, el altar y los rituales que acompañan dicha ceremonia se disponen, por todas estas razones, en los patios traseros o al interior de las residencias, como fue el caso del toque de tambor en casa de Othón. Cuando los recursos lo permiten, se rentan espacios más amplios como salones para fiestas que permiten una recepción más amplia y cierta privacidad. ${ }^{17}$ En otros momentos esta ceremonia puede ser ofrecida a la orilla del mar.

En los toques de tambor, se despliegan y fomentan intercambios entre iniciados y deidades, pero también entre los asistentes (no siempre iniciados) y los anfitriones. Los bienes intercambiables no son exclusivamente materiales, sino también simbólicos (prestigio, solidaridad, alianza, afecto, reconocimiento.....$^{18}$ Asimismo fortalecen las jerarquías y refuerzan las convenciones de las relaciones de las familias de religión o casas de santo. Éstas se forman por el conjunto de personas unidas por lazos de parentesco ritual establecidos por la iniciación. El padrino o una madrina serán -idealmente- los mentores de sus ahijados y en su calidad de "mayores" los encargados de transmitir a sus menores la tradición ritual de la casa de santo, familia de religión o del linaje religioso al que pertenecen. En México, estos lazos se refuerzan con el parentesco biológico con el que se entrecruza y hacen de estas familias una

${ }^{15}$ Entrevista a Mago L., Mérida, Yucatán, 16 de enero de 2008.

${ }^{16}$ Practicantes y devotos del Palo Monte y sus variantes, un culto de origen bantú cuyo centro de veneración es la prenda o la Nganga en donde reside el espíritu de un muerto con el que se pacta.

${ }^{17}$ En algunos puertos como Acapulco, Veracruz, Campeche, Sisal y Progreso, cuando esta ceremonia se hace en honor a Yemayá, se lleva a cabo a orillas del mar.

${ }^{18}$ Cabe señalar que todo iniciado en la santería deberá ser "presentado ante el tambor" como parte de los rituales del proceso iniciático, pues a través de $A \tilde{n} a ́$, la deidad que habita en los batá (trío de tambores sagrados), se da conocimiento a Olodumare que el iniciado en cuestión ha sido consagrado con un orisha. En razón de ello estos toques de tambor a menudo se aprovechan también para efectuar dicha ceremonia. 
institución confiable para bregar con los hijos problemáticos o familiares, las enfermedades, las pérdidas, los problemas de justicia, de dinero, de amor, de la vida.

La diferenciación entre jerarquías dentro de esta religión se expresa, entre otras formas, a través de los saludos. Los menores saludan a sus mayores tirándose a sus pies $^{19}$. A este respecto un iniciado me señala "[...] cuando se hace el moforibale [saludo], en realidad al que se saluda es al santo que tiene [la persona] mayor en la cabeza, el más joven deberá saludar al más viejo como símbolo de respeto." El mayor entonces se inclina y "levanta" a su menor tocándole los hombros y mientras lo pone de pie en voz alta dice: que el orisha $(\mathrm{X})$ te bendiga y te levante. La figura del santo se convierte así, en una mediación simbólica que posibilita y mantiene la diferenciación entre rangos, expresada en la postración, una obligación social adquirida con la iniciación. ${ }^{20}$

Al pie del altar se coloca normalmente una estera y junto, un plato con velas y una canasta en la que se deposita el "derecho" para el santo (reciprocidad de dones diría Marcel Mauss). Los invitados, en especial los ahijados, aportan como derecho, dinero y ofrendas de diversos tipos (cocos, ñames, frutas, flores, velas) que son, de acuerdo con lo que comenta un iniciado: "para darle luz al orisha y de la misma forma él iluminará nuestras vidas, nuestro camino y nuestro entendimiento". En este acto también han "devuelto" parte de lo recibido dentro de su familia de religión, aunque el establecimiento de lo que "se da, se recibe y se devuelve" produce tensiones y fricciones. Por ejemplo, para el toque de tambor de Othón, varios de sus ahijados se quejaron entre ellos porque su padrino no les dejó el "derecho" a voluntad, sino que les pidió "una cuota”. En señal de desacuerdo y molestia, algunos prefirieron no asistir. Otros por el contrario, justificaron dicha solicitud debido a los gastos que implican una ceremonia de este calibre, especialmente en el interior del país en donde son bastante elevados (para la población promedio en México). Los percusionistas vienen normalmente desde la CDMX, tanto mexicanos como cubanos, y más recientemente venezolanos, para poder satisfacer esta demanda ritual. La distancia es por tanto un factor que sube los costos. En promedio, los músicos cobran entre 15 y 20 mil pesos (800-1000

${ }_{19}$ La postración cambia de acuerdo con el santo coronado.

${ }^{20}$ G. Brandon, Santería from Africa to the New World: The Dead Sell Memories, p. 151; M. Atwood, "I Bow my Head to the Ground": The Creation of Bodily Experience in a Cuban-American santería Initiation, p. 32. 
USD) sólo por percutir; a lo que se suma el transporte aéreo, hospedaje y comida; además de todos los insumos para los invitados, es decir que un tambor puede rebasar fácilmente los 40 mil pesos (2000 USD). En razón de lo anterior y cuando las buenas relaciones entre casas de santo lo permiten, varios se dividen los gastos y se aprovecha mejor la estancia de los tamboreros.

\section{Los tronos y rincones de devoción: retrato etno- gráfico de la convergencia de tradiciones}

"El muerto parió al santo" reza un dicho muy concurrido entre santeros, para hacer patente la importancia que tienen los espíritus y muertos en esta religión, a los que también se les atiende y ofrenda. Los días previos a un toque de tambor, se le "da de comer" al "muerto" (egun), es decir, se le rinde culto a los ancestros para recibir su apoyo, y también se da tributo a Eleguá, el orisha que abre y cierra los caminos, evitando así "que haga de las suyas". También se alimenta al orisha al que se le dedica el toque de tambor, normalmente con algún animal de su preferencia. A todas estas figuras se les consultará con el oráculo para saber si están conformes o si hace falta algo más para dar luz verde a la ceremonia que se les anuncia, en este caso el toque de tambor.

Los muertos o egun tienen sus propios espacios devocionales, distintos y separados del de los orisha, pero ambos están entrelazados en la praxis y articulan la complementariedad entre santería, espiritismo y palo monte ${ }^{21}$ que junto con la devoción a vírgenes y santos constituyeron en Cuba lo que históricamente se conoce como santería o Regla de Ocha ${ }^{22}$. En México esta complementariedad de origen se refuerza y va sumando otras prácticas ${ }^{23}$.

${ }^{21}$ Véane nota de pie núm. 16.

${ }^{22}$ Véase, K. Argyriadis, La religión à La Havane. Actualité des répresentations et des pratiques cultuelles havanaises.

${ }^{23}$ Véase N. Juárez Huet, Religiones afroamericanas en México: hallazgos de una empresa etnográfica en construcción, [www 01], pp. 219-241. 


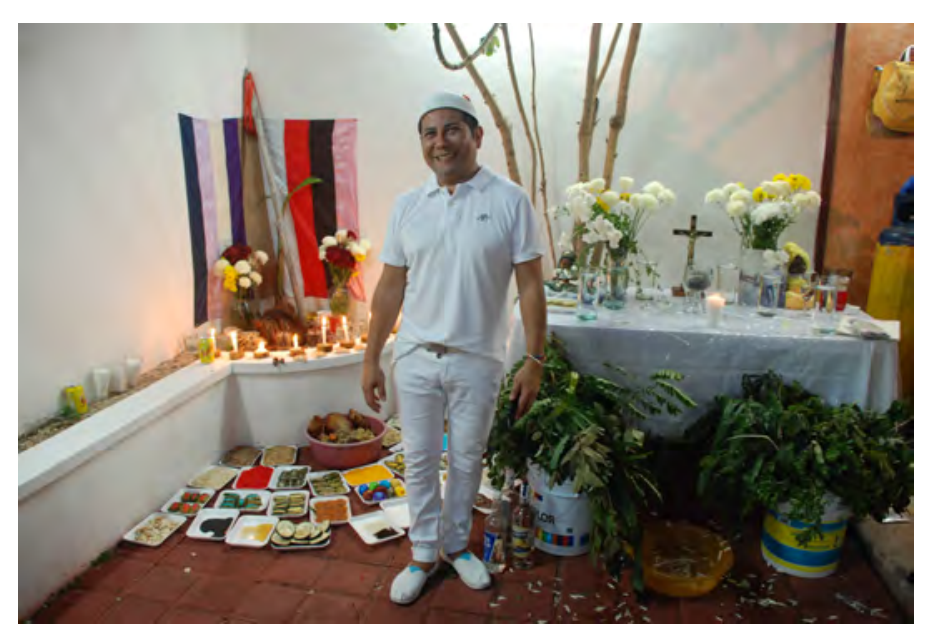

Figura 3: Espacio devocional para egun (izq.) y los espíritus (der.), Mérida, Yucatán, 2015. (Foto: Nahayeilli Juárez Huet)

Darle de comer "al muerto" (egun) como parte de los rituales del toque de tambor es un procedimiento que se observa en las casas de santo de "tradición criolla”, es decir, cubana. En esta ocasión Othón prescinde de la misma y sólo pide la aprobación de su orisha tutelar dado que él, aunque se inició bajo la tutela de padrinos cubanos, en los últimos años entró en contacto con la vertiente religiosa que busca "volver a las raíces" (africanas), a través de la depuración y reorientación de ciertos aspectos rituales y simbólicos de la santería, siguiendo el "modelo yoruba" de Nigeria, es decir "el modo de hacer ritual" de un mentor y padrino iniciado en Nigeria que aceptó "adoptarlo". Se trata de un puertorriqueño practicante de lo que él mismo denomina "la auténtica tradición orisha de África occidental".

En efecto, el parentesco ritual en la santería es una organización social muy dinamizada por la ruptura y reacomodamiento entre padrinos y ahijados y por las pugnas en torno a la "tradición"; pero toda tradición, como bien lo señala Matory, es siempre "una función de poder, negociación y recreación estratégica" ${ }^{24}$. Es en este sentido que la tradición no es cosa del pasado, sino que se reactualiza en el presente, realizar la tradición es "interpretarla" e "[...] interpretar implica siempre una mediación, una síntesis entre conservación y transformación; un movimiento, un desarrollo [...en esa medida es] una infinidad de posibilidades" 25 .

${ }^{24}$ J. L. Matory, La religión del Atlántico Negro. Tradición, transnacionalismo y matriarcado en el candomblé afrobrasileño, p. 79.

${ }^{25}$ M. T. Ramírez, El tiempo de la tradición”, pp. 178-179 
Ahora bien, la santería y la tradición orisha trasatlántica a la que pertenece, requiere forzosamente para toda iniciación de varias personas. Como bien lo señala Argyriadis analizando el caso de Cuba:

"Aun cuando se trata de un(a) religioso(a) con conocimiento, experiencia y numerosos ahijados, la presencia de los demás es imprescindible por dos razones fundamentales: la primera, para acumular fuerza, luz y aché; $y$ segunda, para testimoniar la ceremonia” ${ }^{26}$. Hay, pues, una relación ritual de interdependencia y complementariedad ${ }^{27}$, esto empuja a aquellos que rompieron con sus primeros mentores, a buscar una casa de santo o un padrino o madrina con el que haya afinidad, comprensión, interés mutuo, y por tanto un diálogo y praxis conjunta que van reactualizando las prácticas. De esta manera, el lazo de Othón con su nuevo padrino implicó una reactualización a través de ciertas ceremonias, de la enseñanza y la colaboración ritual. Esta es la razón que explica el porqué ha dejado de usar el coco para el oráculo (como se usa en Cuba) y lo haya sustituido por el obí (nuez de kola como se usa en Nigeria); que su rincón de muerto (egun) haya sido transformado, o bien que prescinda de las soperas y calderos de varios orisha en su altar. Lo anterior no implica sin embargo hacer tabula rasa, porque como dice Othón "al buen amigo no se le olvida, por eso mi sopera criolla [cubana] la ves con el receptáculo [nigeriano] de Yémojá” 28 (tal como lo pronuncia Othón evocando la pronunciación yoruba de este orisha).

${ }^{26} \mathrm{~K}$. Argyriadis, 2005, El desarrollo del turismo religioso en La Habana y la acusación de mercantilismo, Desacatos, Núm. 18, p. 36

${ }^{27}$ D. Brown, Santería Enthroned: Art, Ritual, and Innovation in an Afro-Cuban Religion; E. Gobin, Les religions d'origine africaine à La Havane. Ethnologie d'une harmonie rêvée.

${ }^{28}$ Pronuncia como su padrino -hablante de lengua yoruba- le ha enseñado. Entrevista a Othón C., Mérida, Yucatán, 29 de marzo de 2012. 


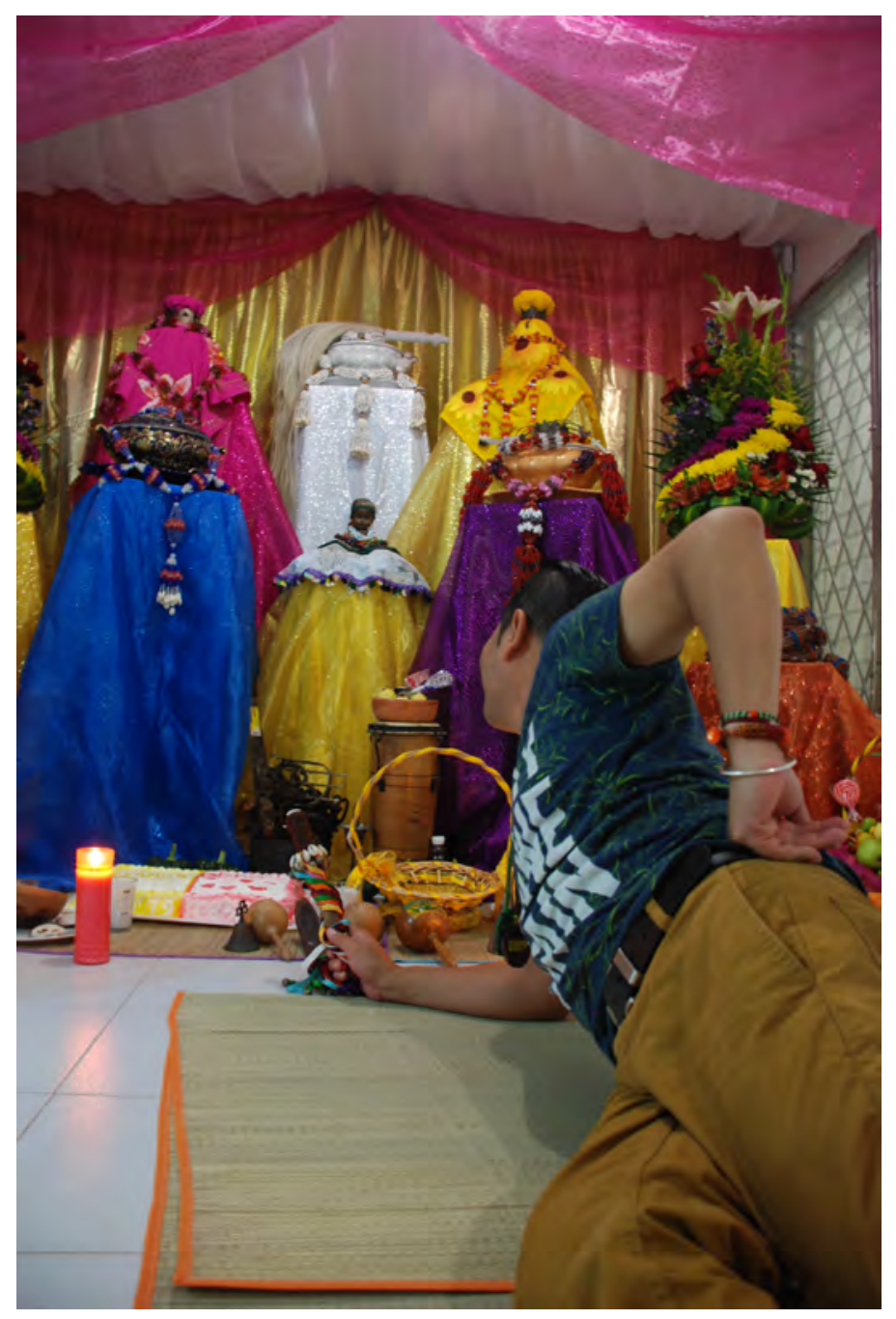

Figura 4: Saludo al trono. Al centro del mismo, el orisha Obatalá (en blanco) en honor a quien se ofrece el tambor. Mérida, Yucatán, 2015. (Foto: Nahayeilli Juárez Huet)

En todo toque de tambor se dispone un espacio devocional denominado trono. Se trata de un espacio cuidadosamente decorado en el que se despliegan las representaciones y soportes materiales (soperas que contienen sus secretos) e iconográficas de las deidades veneradas. El trono de Othón y de su esposa, justamente permitía resaltar la cohabitación de dos variantes de una misma tradición trasatlántica. Othón conserva a los santos recibidos en su ceremonia de iniciación, pues en la tradición cubana además del orisha tu- 
telar o "santo de cabecera", se entregan otros orisha (entre cinco y seis) con sus respectivas representaciones materiales. Normalmente, en los tronos de la tradición criolla todos estos orisha se colocan en el espacio de devoción y acompañan al orisha festejado, el cual se coloca al centro junto con los objetos que evocan sus atributos más destacados. Otros accesorios adornan este espacio, como los collares de mazo (usados en la iniciación) y todos los elementos representativos de estas deidades: coronas, colas de caballo, abanicos, herramientas, juguetes, animales de mar hechos en cerámica, además de la comida de su preferencia, y una copiosa ofrenda de frutas. Es el espacio de recepción de la fiesta y en donde todo invitado pasa a dejar su derecho y "saludar" a los orisha, para lo cual se disponen los instrumentos adecuados. Para Changó la deidad del trueno, del fuego, de la guerra, se utiliza una maraca; cuando se le honra a Obatalá, el dueño de las cabezas, se utiliza una campana de metal; a Ochún, orisha de la fertilidad, una campana de cobre; a Yemayá la dueña del mar una sonaja y así a cada orisha.

Como se aprecia en la Figura 2, el altar que desplegó Othón presenta diferencias con respecto a los tronos criollos (Ver figura 4). Debido a que el toque de tambor está dedicado a Yemayá y Oshún, deidades de agua, ambas son representadas en el altar. Del lado derecho se colocaron juntas a la "Yemáyá criolla" (cubana) pero también a la "Yémọjá africana", la que él recibió de su padrino adoptivo y que vive en agua, es decir que sus fundamentos están contenidos en un recipiente con agua, en este caso una jícara cubierta por una tela azul que no permite verla.

Yeni su esposa, iniciada por el mismo padrino que Othón, me acompañó aquel día hasta el trono para mostrarme a su Oshun y explicarme que en Nigeria, Oshun usa también el color verde, en sus telas y collares, a diferencia del amarillo tenido como emblemático en Cuba. En un pedestal se colocó así a la Oshún criolla, que fue la que Othón recibió cuando se inició en la santería; junto a la Oshun de Yeni en su versión nigeriana. Se trata de una jícara cuyos íconos también están cubiertos con una tela. En ambos lados se colocó igualmente una representación antropomorfa de ambas deidades. Destacaba la sirena, asociada a un camino de Yemayá. Dicen que no hay más que una sola Yemayá, con varios caminos. La Yemayá más vieja -agrega la investigadora cubana Lydia Cabrera- tiene escamas y cola de pez, en el agua cobra forma de sirena ${ }^{29}$. Sin embargo, en América, en el contexto del imperio católico desde el virreinato, se asociaron muchos de sus caminos con diversas

${ }^{29}$ L. Cabrera, Yemayá y Ochún, p. 32. 
advocaciones de la virgen María, comúnmente presentes en los altares de México y Cuba, en donde la virgen de Regla es, para los santeros, un camino de Yemayá. En el trono de Othón y Yeni, se prescindía completamente de cualquier imagen católica, ya que ahora ellos asumen su vertiente "yoruba" y la usanza ritual nigeriana.

A este respecto Yeni señala: "Yo crecí en el criollo [tradición cubana], no lo estoy criticando pero quise africano porque ese es el origen, así me lo contaba mi mamá, que nunca se pudo hacer nada [ceremonias de iniciación] ni a nosotros, porque, figúrate tú, o comíamos o teníamos santos”. Oshun se entrega en dos contenedores y no uno solo - me recalca- como es el caso de la tradición cubana. En uno, come [cuando se le alimenta con la sangre de un animal] y en otro se venera. Ya que según Yeni, Oshun es un orisha "muy limpia y presumida, a ella no le gusta la suciedad". ${ }^{30}$

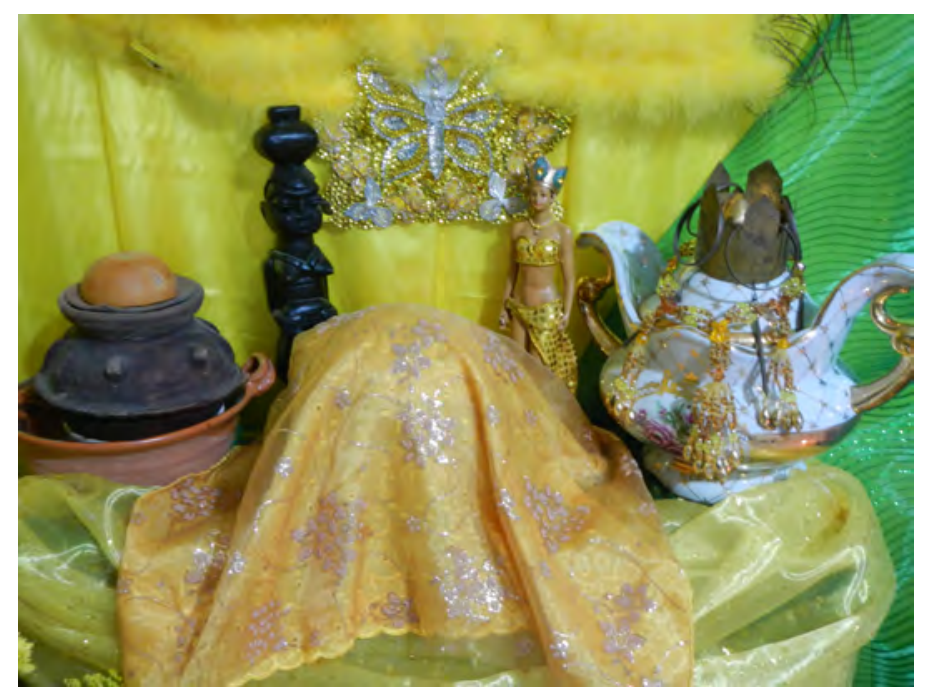

Figura 5: Detalle del trono de Othón y Yeni. Oshún en su representación africana (izq.) y en su representación criolla o cubana (der.) Mérida, Yucatán, enero de 2013. (Foto: Nahayeilli B. Juárez Huet)

\section{Del oro seco y cantado, a la montada}

Para iniciar, los tamboreros se dirigen frente al trono. Una vez vestidos sus tambores y colocada la tela que llevan sobre sus rodillas se disponen a percu-

${ }^{30}$ Conversación con Yeni C., Mérida, Yucatán, 26 de enero de 2013. 
tir. Los tambores que se utilizan en estas ceremonias son los llamados batá, ${ }^{31}$ conformados por "un trío orquestal" Cada uno de los tres tiene un tamaño y un nombre distintos ${ }^{32}$. Al más grande de todos se le llama Iyá, al cual se le coloca alrededor de las dos bocas un cinturón con campanas y cascabeles; el tambor mediano es conocido como omelé o itótele y al más pequeño de los tres como okónkolo. Cuando los batá son consagrados se transforman en tambores de fundamento y en su interior vive Aña. Sólo aquellos hombres "jurados en tambor", hijos del secreto de Aña, "omo Añá" pueden participar en el montaje, lavado y "nacimiento" de estos batá. Es decir, que todos los batá son simbólicamente "paridos” por un batá más viejo, Para percutirlos no es necesario ser "jurado en el tambor", sin embargo, sí es necesaria una ceremonia en la que "te lavan las manos" lo que te da la investidura de Olubatá (que sabe tocar el batá). Las "restricciones" con respecto a los omo añá están regidas por criterios de género y orientación sexual. Las mujeres y homosexuales están excluidos de esta consagración.

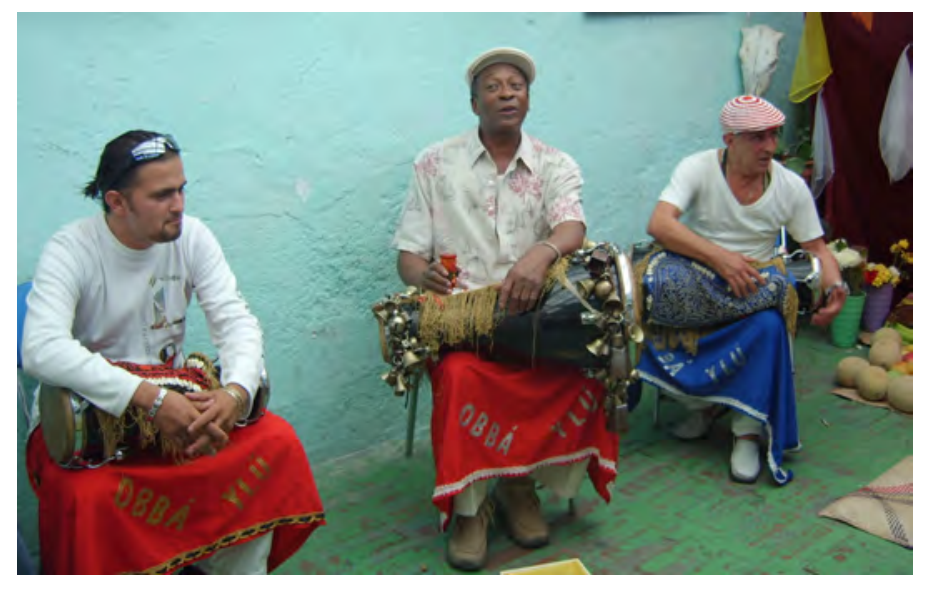

Figura 6: Los tambores batá. Al centro y a la derecha, dos legendarios santeros cubanos en México, además de bailarines y percusionistas. México, D.F. 2008. Foto: Nahayeilli Juárez Huet)

El toque comienza con lo que se conoce como oro seco "la verdadera fiesta para el santo, tributo que se le ofrenda con música para que esté contento con nosotros" - me comenta un asistente. En este lapso no se baila ni se canta, sólo se percute para los orisha. El oro seco dura aproximadamente

${ }^{31}$ F. Ortiz, 1995, Los instrumentos de la música afrocubana. Los tambores batá, pp. 6-7.

${ }^{32}$ Ibidem, p. 6. 
entre tres cuartos de hora y una hora. Una vez finalizado, se hace una pausa. Los tamboreros son alimentados antes de proceder a ejecutar el oro cantado. Siempre se comienza con un canto para Eleguá y así sucesivamente por una hora aproximadamente, durante la cual, los iniciados saludan al tambor. Se abre la tercera parte que es el baile, probablemente la más emotiva y amena de todas. La gente se va incorporando, se anuncia el turno de cada orisha honrado y en su honor se reproducen los cantos y movimientos corporales que les corresponden. Por ejemplo, cuando se baila para Ogún todos sus hijos pasan al frente y de un lado y otro levantan y bajan los brazos simulando su personalidad de guerrero con un machete abriéndose paso. Cuando se evoca a Yemayá se forma un círculo y la gente imita el movimiento del mar, las mujeres se ayudan tomando sus faldas de los lados haciendo "olas más grandes”. Los hijos de Obatalá, el orisha más viejo de todos, se joroban y dejan las manos colgando hacia el frente, haciendo pasos lentos y pequeños. $\mathrm{Y}$ así cada iniciado sigue el ritmo como puede, cuando de su orisha se trata. Lejos de ser circunspectos, en estos eventos uno puede experimentar -como dice la gente- "tremenda gozadera".

\section{5 "No es lo que baila, sino lo que te habla"}

El tiempo transcurre y el tam-tam sube y baja los acentos de los golpes sobre el cuero del batá, que junto con sus campanas cimbran las emociones y entran en diálogo con el canto y el baile. Dentro de la casa de Othón, el calor y el ritmo va subiendo, subiendo, subiendo, y con la subida los cuerpos más se sacuden, uno de los presentes comienza a bailar aparentemente sin control, con los ojos cerrados bota su camisa, y comienza a hablar de manera extraña, nadie parece entenderle. Fue retirado "a regañadientes" de la escena por el mismo anfitrión que lo invitó a pasar al patio sin mayor explicación. Entre los murmullos de las interpretaciones sobre lo acontecido el toque continúa.

Y es que todavía los cubanos no tienen mucha competencia en México en lo que se conoce como "Montar santo", para referirse que un orisha "baja" y hace posesión del cuerpo de alguno de sus hijos, es entonces que lo "hace su caballo", "lo monta". Aunque se trata de un tema muy controversial, la presencia de un orisha se manifiesta a ojos de muchos de sus devotos en el dominio del performance corporal y de hablar "en lengua" (lucumí). A cada orisha le corresponden coreografías particulares que se socializan y transmiten dentro de la comunidad religiosa. Aquí el que no "da pruebas" se le 
descalifica y sanciona con la mirada, con la indiferencia, con la sonrisa burlona que busca dejar en evidencia al "farsante". Y es que no todos los santeros son montadores. Un cantante y santero cubano me señala a este respecto: "lo mismo que en México, que en Cuba, que en Australia o Madagascar, ¡al que le da! ¡le da! [es decir, el que monta de verdad lo puede demostrar en cualquier parte] pero a la mayoría no le da na'a' [nada] yo por eso paro el tambor"33. Parar el tambor significa detener la música de golpe, como una manera de no permitir que el "simulador" robe un escenario que no le pertenece. En efecto, muy frecuentemente entre santeros se dice que la montada de santo puede prestarse al puro "show": "porque el santo da pruebas cuando baja y no por que te pongas a dar vueltas y gritos o te avientes al piso contorsionándote como le hacen unos, significa que el santo te ha montado". Esas fueron las palabras de un difunto babalawo que tenía más de 30 años en la religión y dueño de dos juegos de batá. Por ejemplo -me explicaba- si hay alguien que está montando Changó:

"[...] tú le dices [cantando] ainá lodé Chango bara egbodé, Chango bara egbodé, Chango bara egbodé, aina take, take take ${ }^{34}$. ¡Come candela para saber si tú eres Changó! si la persona no sabe nada y lo que quiere es vernos la cara a todos [tomarnos por tontos], entonces no hace nada de lo que está diciendo el canto, pero si es Changó se encabrona [se enoja] y viene y se monta, va y agarra candela y se la come, se la mete a la boca ¡Él ya te probó que es Changó! pero después él viene y te dice ¡come tú! entonces tú también debes de responderle emi alato kuyu egbode emi alato kuyu egbode titila...Changó... tú eres Changó, tú comes Candela, pero yo no soy Changó, yo te estoy pidiendo a ti que te la comas, porque tú eres Changó, pero tú no puedes pedirme a mí que me la coma porque yo no soy Changó, yo no soy nadie. Entonces se le piden disculpas al santo por la ofensa que se le hizo; es para probar que es efectivamente el santo es el que viene y evitar que un mentiroso nos vea la cara, una persona que monta de verdad se le tira al tambor, saluda al tambor mayor porque es el que llama a los santos, después saluda al chico y después al

${ }^{33}$ Entrevista a Oriaté Akpwon R., Mérida, Yucatán, 9 de julio de 2012.

${ }^{34}$ En este testimonio todas las palabras en "lucumí” (en cursivas) están escritas de acuerdo con la fonética del entrevistado. 
mediano, después de saludar a los tres tambores saluda inmediatamente al trono y después va con los babalawos y aunque no los conozca se les tira, los saluda, esto cuando es un santo [orisha] de verdad..." 35

El akpwon, es decir el cantante ritual que dirige los cantos a los orisha, pieza fundamental en los toques de tambor, es clave para "ponerle sabor", es quien conoce los cantos que llaman al orisha y provocan que se manifieste. Hoy, este papel está dominado por hombres, tanto en México como en Cuba, en donde se dice que alguna vez existieron tremendas cantantes. El apwon dirige el coro de los presentes y es ante todo, el que "sabe si el santo está o no [presente], es un diálogo entre el cantante con el santo montado, se dicen cosas, uno llama al santo" 36 . Y es que un "buen montador" debe demostrarlo por medio de los gestos corporales que corresponden al orisha que monta pero sobre todo y principalmente, a través de sus consejos, de lo que habla. Si el santo monta, tendrá ashé y por tanto el mensaje que transmite del orisha que lo monta "será certero". Este acontecimiento es, según afirmó uno de mis dialogantes, "el punto de éxtasis en nuestra religión, porque el santo baja y te habla".

Cuando el orisha finalmente monta su caballo, éste es retirado de la escena momentáneamente y se le viste de acuerdo con los atributos del orisha en cuestión. Así por ejemplo, si baja Yemayá, a la persona montada se le viste con una falda o vestido azul; o si se trata de Ogún con un pantalón corto y falda de paja, banda de cabeza y machete, y así sucesivamente. También entran en escena los traductores que acompañan al montado, el cual se supone que habla en "lucumí" (adjetivo con el que se designaba en Cuba a esclavos yoruba). Alguien más estará a su lado acercándole agua, miel o manteca de corojo, dependiendo del orisha. Sus predicciones, advertencias y bendiciones son acompañadas en señal de confirmación del coro enérgico que grita ¡ashé! y que sale de voz de los mayores que se encuentran cerca o que lo asisten. El montado a veces se dirige al trono y toma algunos collares de mazo (collares de iniciación) que pone en el cuello de ciertos asistentes y de esta forma "los prende", lo que quiere decir que deberán iniciarse en algún momento. Algunos montadores "limpian" a los asistentes con frutas del trono, pasándoselas por todo el cuerpo. A veces restriegan su cabeza en el pecho y vientre de

${ }^{35}$ Nota: la escritura está basada en la pronunciación que yo entendí y escuché. Entrevista a L. Gámez, México, D.F., 4 de octubre de 2004.

${ }^{36}$ Entrevista a Oriate y akpwon, R. ídem. 
aquellos que de acuerdo con el criterio del orisha deben ser "despojados" de lo malo. El montador es pues un mediador, el soporte físico de la manifestación del orisha.

En Mérida no existen montadores "profesionales", como se observa para el caso de la ciudad de México, es decir, personas que se "levantan" (contratan) para tal tarea, que en su gran mayoría siguen siendo cubanos. Esto podría explicarse porque pienso que los orisha siguen siendo todavía, en términos de Felicitas Goodman, "específicos culturalmente", ${ }^{37}$ es decir, cubanos. Sólo en rituales de la santería, los espíritus que se montan serán estas deidades; así como en un ritual de evangélicos será el espíritu santo. La coreografía corporal y el dominio de la "lengua" atribuidos a los orisha, provienen de un estilo predominantemente cubano, ampliamente socializado y por lo tanto reconocido y legitimado. Los mexicanos aún no incorporan cabalmente este lenguaje corporal, aunque eso no les impide extasiarse a pesar de las "sanciones" simbólicas.

Un toque de tambor puede durar en promedio seis horas. Transcurridos los cantos y bailes a todos los orisha, para cerrar se trae una cubeta con agua que se coloca frente a los tambores. La gente mueve el cuerpo casi en su propio eje y con pasos cortos, es aquí donde todos tienen oportunidad de "limpiarse". El gesto correspondiente es con la palma de una mano semiabierta que se pasa sobre la cabeza en semicírculo, simulando que uno quita y se sacude algo, una y otra vez; o bien con los brazos levantados, ambas manos abiertas y sacudiéndolas. Un designado toma la cubeta. Vierte con la mano que le queda libre un poco de agua sobre el piso frente a cada tambor, a veces se retira dando vueltas sin soltarla, otras, sale a la calle lo más rápido posible para tirar el agua y volver de la misma forma en la que se fue. Se dirige hacia los tambores y coloca la cubeta boca abajo de un solo golpe. Minutos después los batá cesan su "voz", la fiesta ha terminado.

En el tambor, como en la mayor parte de los rituales santeros, se da y se recibe ashé (aché), la fuerza oculta que ocupa al universo, el poder que emana de Olodumare, transferido a los orisha y sus devotos para hacer que las cosas pasen. Así, los asistentes, antes de partir, pasan al trono para llevarse fruta y pastel de la ofrenda, que difícilmente puedes rechazar, pues el anfitrión siempre te recuerda que a través de estos alimentos uno recibe también ashé.

${ }^{37}$ F. D. Goodman, Las múltiples caras de las posesiones, p. 102. 


\section{Notas finales}

El análisis etnográfico a través de la praxis religiosa y cotidiana concreta permite por un lado, comprender de manera más fina la dimensión subjetiva de las creencias; y por el otro, las lógicas de las redes y sentidos de pertenencia y autoadscrpción religiosa de los santeros mexicanos. Los orisha y los muertos personales y la existencia de medios y técnicas para entablar comunicación con ellos, se erigen como bisagras fundamentales de la santería para su aceptación cada vez más amplia en México. Esta religión, de origen afrocubano, practicada en el país desde los años 70, no se opone a las creencias previas que forman parte de la visión del mundo de los mexicanos que a ella se acercan y que son personas que mayoritariamente oscilan entre los 25 y 60 años. Estos devotos desvelan el destacado papel que ha tenido no solamente el catolicismo popular, sino el espiritismo en sus diversas variantes y la medicina "tradicional" que trabaja con santos y las mancias de gran arraigo en México, que se han articulado con la santería dándole otras pautas de relocalización.

Aunque el catolicismo se sigue manteniendo como un marco estructurante y sigue siendo mayoritario en México, es claro que estamos muy lejos de un apego fiel a su doctrina y sus reglas institucionales, pues los santeros por lo general no han dejado de considerarse católicos, pero sus prácticas no se limitan a lo que dicta la doctrina, lo que pone en evidencia la actual dislocación observada en América Latina entre creencia, práctica y adscripción.

Por otro lado, la complementariedad no se da sólo con estas prácticas, sino dentro de las mismas variantes de la tradición orisha. En este texto se mostró apenas, a través de la tendencia más contemporánea de la búsqueda de las "raíces" (yoruba), un proceso que implica ciertas disputas definidas más por los contextos y las coyunturas, que por la supuesta "pureza" de los rituales en cuestión. La tradición en efecto, implica siempre una negociación estratégica ${ }^{38}$ "hay sus rupturas y con ellas el establecimiento de nuevos caminos que en su recorrido forman nuevas tradiciones reinventado los "orígenes". Las tensiones sobre los "modos correctos de hacer" tienen también diversas intensidades y muchas de sus soluciones se dan en la escala más íntima del practicante, en donde es él, quien tiene la última palabra. Lo anterior pone en evidencia el papel fundamental que juega la agencia individual en la vida religiosa contemporánea, sobre el que puedan tener los administradores institucionales y oficiales de la fe; además de que nos aleja de una visión de

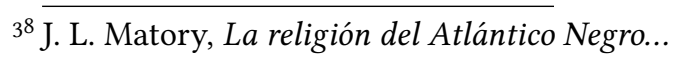


doctrinas, prácticas o adscripciones religiosas con fronteras tajantes y claramente delimitadas.

\section{Bibliografía}

1. Argyriadis K., 1999, La religión à La Havane. Actualité des répresentations et des pratiques cultuelles havanaises, Éditions des Archives contemporaines - Centre d'Antropologie des Mondes Contemporains, EHESS, París 1999.

2. Argyriadis K., El desarrollo del turismo religioso en La Habana y la acusación de mercantilismo, "Desacatos", Núm. 18 (2005), pp. 29-52.

3. Argyriadis K. y De la Torre R., Introducción, en K. Argyriadis, R. De la Torre, C. Gutiérrez Zuñiga y A. Aguilar Ros (Éds), Raíces en Movimiento. Prácticas religiosas tradicionales en contextos translocales, El Colegio de Jalisco, Zapopan, Jalisco 2008, pp. 11-42.

4. Atwood M., 1994, "I Bow my Head to the Ground": The Creation of Bodily Experience in a Cuban-American santería Initiation, "Journal of American Folklore", vol. 107, núm. 423, pp. 22-39.

5. Brandon G., Santería from Africa to the New World: The Dead Sell Memories, Indiana University Press, Bloomington 1997[1993].

6. Brown D., Santería Enthroned: Art, Ritual, and Innovation in an AfroCuban Religion, Universidad de Chicago, Chicago 2003.

7. Cabrera L., Yemayá y Ochún, C. R. Publishers. Colección del Chicherikú, Nueva York 1980 [1974].

8. Goodman F. D., Las múltiples caras de las posesiones, "Alteridades" (Universidad Autónoma Metropolitana), vol. 6, núm. 12 (1996), pp. 101116.

9. Gobın E., Les religions d'origine africaine à La Havane. Ethnologie d'une harmonie rêvée, memoria de Maestría, Universidad de París X, Nanterre 2003.

10. JuÁRez Huet N., Religiones afroamericanas en México: hallazgos de una empresa etnográfica en construcción, "Revista Cultura y Religión”, Vol. VIII, $\mathrm{N}^{\circ} 1$ enero-junio (2014), [www 01], pp. 219-241.

11. Matory J. L., La religión del Atlántico Negro. Tradición, transnacionalismo y matriarcado en el candomblé afrobrasileño, Editorial del Caribe, Editorial de Oriente, Santiago de Cuba, Cuba 2015 [2005]. 
12. Orsi R. A., Between Heaven and Earth: The Religious Worlds People Ma$k e$ and the Scholars Who Study Them, Princeton University Press, New Jersey 2005.

13. Orsi R. A., Is the Study of Lived Religion Irrelevant to the World We Live in?, "Journal for the Scientific Study of Religion" 2 (42), 2003, 169-174.

14. Ortiz F., Los instrumentos de la música afrocubana. Los tambores batá, Letras Cubanas, La Habana 1995.

15. Simmel G., El extranjero. Sociología del extraño, Sequitur, España 2012.

16. Verger P., Dieux d'Afrique, Éditions Revue Noire, Paris 1995 [1954].

17. Ramírez M. T., El tiempo de la tradición, "Relaciones" vol. 21, núm. 81 (2000), pp. 163-185.

\section{Fuentes de internet utilizadas:}

[www 01] http://www.revistaculturayreligion.cl/index.php/culturayreligion/ article/view/455 


\title{
Abstract, keywords, about the author
}

\begin{abstract}
This study describes how does the everyday religious life work, the network of relationships between the initiated in Afro-Cuban Santeria, as well as those involving themselves and the sacred figures which they worship, represented by the orishas. Far from exhausting the vast wealth of Santeria as a religion vivida the study focuses only on the ceremony of toque de tambor as an illustrative example of the complexity that characterises relationships within the Mexican context, where on the one hand a social regulation exists that prohibits the religious diversity in which Santeria participates, and on the other a dislocation between religious affiliations, practices and beliefs, which denote a deinstitutionalisation of the religious as observed in general in contemporary Latin America.
\end{abstract}

Keywords: Religión vivida, Santeria, Mexico, toque de tambor, orisha

Nahayeilli B. JuÁrez Huet is a Social Anthropologist and a professor at the Centro de Investigaciones y Estudios Superiores en Antropología Social (CIESAS Peninsular). Her academic interests cover the circulation of Afro-American religions and new spiritualities of the New Age.

E-MAIL: nahahuet@ciesas.edu.mx 